\title{
Spatiotemporal Variations of Hydrologic Extremes and Response to Extreme Precipitation in Xiang River Basin
}

\author{
Linlin Cheng ${ }^{1,2,3}$, Juan $\mathrm{Du}^{1,2,3^{*}}$, Yumeng Yang ${ }^{1,2,3}$ \\ ${ }^{1}$ Key Laboratory of Environmental Change and Natural Disaster, Ministry of Education of China, \\ Beijing Normal University, Beijing 100875, China \\ ${ }^{2}$ State Key Laboratory of Earth Surface Processes and Resource Ecology (Beijing Normal \\ University), Beijing 100875, China \\ ${ }^{3}$ Academy of Disaster Reduction and Emergency Management, Ministry of Civil Affairs \& \\ Ministry of Education, the Peoples' Republic of China, Beijing 100875, China
}

\section{湘江流域水文极值的演变特征及对极端降水的}

响应

\author{
程琳琳 $1,2,3$, 杜鹃 $1,2,3^{*}$, 杨雨蒙 ${ }^{1,2,3}$ \\ ${ }^{1}$ 北京师范大学环境演变与自然灾害教育部重点实验室, 北京 100875 , 中国 \\ ${ }^{2}$ 地表过程与资源生态国家重点实验室 (北京师范大学), 北京 100875, 中国 \\ ${ }^{3}$ 民政部/教育部减灾与应急管理研究院, 北京 100875 , 中国
}

\begin{abstract}
Trends of streamflow and water level extremes are significant indicators reflecting the risk of floods and droughts. The study on trends of hydrologic extremes can provide references for water resource management and flood risk analysis. Based on Mann-Kendall test, this article detected existing trends in extreme streamflow and water level in the Xiang River basin that are most afflicted by frequent and severe floods. Subsequently, continuous wavelet transform method was employed to identify the consistency of changes in extreme precipitation and streamflow. The results show that no significant trends can be detected in annual discharge extremes in Xiang River basin, but the summer high flows show positive trends in the most area of upper and middle river basin. The results of wavelet transform analysis illustrate that highly similar
\end{abstract}

基金项目：国家自然科学基金资助项目（41401097） patterns of signal changes can be seen between extreme precipitation and streamflow in upper and middle section of the basin, while the changes in extreme precipitation for the lower reaches do not always coincide with the extreme streamflow.

Keywords: Xiang River basin; extreme streamflow and water level extremes; extreme precipitation; Mann-Kendall test; continuous wavelet transform

\section{摘要}

河川极端径流量和水位变化特征是反应洪水或干旱 风险的重要表征, 对其长期变化规律的研究结果可为 该区域的水资源管理与洪水灾害风险研究提供重要 的参考。本文以频受洪水严重威胁的湘江流域为研究 对象, 采用非参数的 Mann-Kendall 方法对该流域 1976-2012 年历史观测极端河川流量和水位的时空变 化进行分析, 以确定流域水文极值的演变特征; 通过 连续小波变换方法, 研究了该流域极端流量对极端降 水的响应。结果表明: 湘江流域的年极端径流没有显

作者简介: 程琳琳 (1989-), 女, 河北人, 硕士研究生, 主要从事流域洪水灾害风险研究。

Email: chengll@mail.bnu.edu.cn

*通讯作者: 杜鹃 (1983-), 女, 湖北人, 博士, 讲师, 主要从事流域水文过程模拟方面的研究。

E-mail: juan.du@bnu.edu.cn 
Risk Analysis and Crisis Response in Big Data Era (RAC-16)

著变化趋势, 而夏季极端径流在 $26 \%$ 水文站显著增加。 小波变换分析结果显示在流域极端降水和径流之间 的信号变化呈现相似的变化模式, 而信号在上中下游 的相似程度呈现下降的规律。

关键词: 湘江流域; 极端流量; 极端水位; 极端降水; Mann-Kendall 检测; 连续小波分析

\section{1. 引言}

联合国政府间气候变化专门委员会 (IPCC) 第四 次评估报告指出 ${ }^{[1]}$, 在 21 世纪全球干湿季节之间的 降水差异将会增大, 强降水的频率、强度和雨量增加, 流域极端降水事件的增加可能会导致干旱、洪涝等极 端水文事件频发损失加剧 ${ }^{[2,3]}$, 对人类的生命财产安 全以及社会的可持续发展构成严重威胁。

近年来, 水文极值变化已经引起国内外众多学者 的关注, 成为水文科学研究的热点问题。研究表明人 类进入 21 世纪以来, 全球超过 20 万平方公里的大流 域百年一遇的洪水频率呈现显著增加趋势 ${ }^{[4]}$ 。Keef 等 ${ }^{[5]}$, Burn 等 ${ }^{[6]}$, Glaser 等 ${ }^{[7]}$ 学者分别对英国、加拿 大和欧洲地区的极端径流变化特征进行了分析, 结果 表明这些地区的极端径流均呈增加趋势。刘九夫等 ${ }^{[8]}$ 对 20 世纪我国暴雨和洪水极值的研究发现，60、90 年代特大洪水极值在我国南部地区发生最频繁。陶望 雄等 ${ }^{[9]}$ 对渭河中段汛期与非汛期径流极值的趋势性、 周期性及其持续性进行了分析与预测, 发现非汛期极 端事件强度呈增加趋势。杜鸿等 ${ }^{[2]}$ 对淮河流域地区的 极端径流的特征进行了分析, 结果显示干流上的站点 均呈现增加趋势。

湘江是长江下游的主要支流之一, 其所在流域是 全国重要的工农业生产基地。近几十年来, 湘江暴雨 洪水灾害频繁发生, 该流域的水文状况已引起学者们 的关注。陈波等 ${ }^{[10]}$ 研究了湘江流域洪涝灾害程度与降 水的关系。杜鹃等 ${ }^{[11]}$ 采用 Mann-Kenda11 趋势检验法 对湘江流域主要水文站 1976-2008 年的径流和水位 的长期变化规律进行了研究。肖艳等 ${ }^{[12]}$ 基于湘江流域 44 个气象站 1960 2007 年的逐日降水资料, 分析了 该流域极端降水事件的变化特征, 研究了不同强度降 水事件的时空分布特征。薛联青 ${ }^{[13]}$ 分析了湘江流域降 雨和径流的突变特征。上述研究对于湘江流域降雨、 径流以及极端降水变化规律进行了分析, 但是对于水 文极值以及其对极端降水的响应方面的研究仍较为 缺乏。多项研究表明气候变化是导致极端径流发生的 主要因素 ${ }^{[1,15]}$, 河流极端径流事件与流域内极端降水 事件常常相伴发生 ${ }^{[16,17]}$ 。因此本文在分析湘江流域水 文极值的演变特征的基础上, 采用小波分析方法分析 了水文极值对极端降水的响应, 对于在当前气候变化
影响下, 理解湘江流域的水文极值演变规律和驱动因 素, 具有重要的科学与现实意义。

\section{2. 流域概况}

湘江流域位于 $110^{\circ} 25^{\prime} \sim 114^{\circ} 20^{\prime}$ E, $24^{\circ} 35^{\prime} \sim$ $28^{\circ} 50^{\prime} \mathrm{N}$, 流域面积为 $94660 \mathrm{~km}^{2}$ 。湘江流域属亚热带 季风湿润气候 ${ }^{[1]}$, 雨量丰沛, 多年平均降水量约为 $1400 \mathrm{~mm}$, 多年平均气温为 $17.6^{\circ} \mathrm{C}$ 左右。湘江是汇入洞 庭湖最大的河流之一, 发源于广西海洋山, 自南向北 注入洞庭湖, 以水文站老埠头站、衡阳站为界划分上 中下游。湘江流域水系发育, 支流众多, 在湖南省境 内河长大于 $5 \mathrm{~km}$ 的大小河流共有 2157 条, 两岸支流 不对称分布。右岸主要支流潇水、来水、春陵水、洣 水、渌水及浏阳河发源于湖南省东南和东部山地, 源 远流长, 水量丰沛, 集水面积大; 左岸支流祁水、蒸 水、涓水、涟水均源于西面山岭, 支流一般短小, 流 程短, 水量相对较小, 集水面积小。

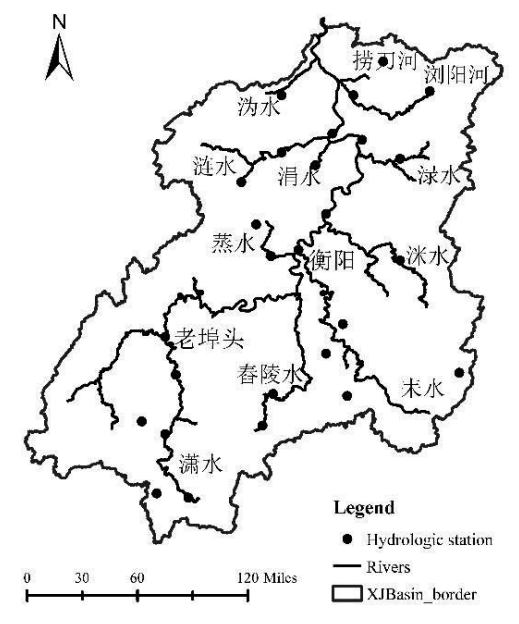

图 1. 湘江流域主要支流及水文站点分布图

本文根据湘江流域 27 个典型水文站点 1969-2013 年的历史日流量资料以及 1969-2013 年中 国地面水平分辨率 $0.5^{\circ} \times 0.5^{\circ}$ 的日降水格点数据, 采用 Mann-Kendall 非参数检验方法, 分析湘江流域 水文极值的时空变化规律, 最后运用 Morlet 连续小 波变换对极端降水与极端径流的周期性进行分析判 断其分布的一致性, 确定极端径流对极端降水的响应 关系。 
Risk Analysis and Crisis Response in Big Data Era (RAC-16)

\section{3. 数据与方法}

\section{1. 数据及数据处理}

本研究搜集了湘江流域气象、水文数据, 并提取 相关指标构建了极端水文事件分析数据库。其中, 降 水原始数据为 $1969-2013$ 年中国地面水平分辨率 $0.5^{\circ}$ $\times 0.5^{\circ}$ 的日降水格点数据, 数据来自中国气象局气 象信息共享服务网。在研究中提取出湘江上中下游地 区及各水文站点汇水区域内的面域夏季最大降水量。 水文数据主要为湘江流域逐日平均流量、水位, 数据 来源于湖南省水文水资源局。剔除部分序列短于 30 年以及数据缺测过多的站点, 流量数据最终选取 27 个站点, 其中上游包含 6 个站点, 中游包含 9 个站点, 下游包含 12 个站点。水位数据选择 19 个站点, 其中 上游包含 5 个站点, 中游包含 5 个站点, 下游包含 9 个站点。提取的主要水文极值指标包括, 湘江干流站 点的年最大流量（水位）、年极端流量（水位）（第 95 分位阈值）、年极端水位（流量）频次、年连续 3 天最大流量、年连续 5 天最大流量等。

\section{2. 研究方法}

3.2.1. Mann-Kendall 趋势及突变检验方法 ${ }^{[18]}$

本研究采用非参数的 Mann-Kendall 检验方法 ${ }^{[19}$, ${ }^{20]}$ 来检测湘江流域极端降水和极端径流的长期趋势 变化及突变变化。Mann-Kendall 检验方法是从样本序 列的秩出发而不是实际数据值来判断两个变量之间 的相关程度, 不需要样本服从特定的分布, 同时有效 避免了水文研究中少数异常值对结果的影响, 因而广 泛应用于水文气象数据的趋势及突变分析 ${ }^{[21,22]}$ 。

在趋势检验中, 原假设 $\mathrm{H}_{0}$ 表示数据集 $X$ 的样本 序列独立同分布, 没有趋势存在。可选假设 $\mathrm{H}_{1}$ 表示 数据集 $X$ 的样本序列存在一个单调的趋势。最后根据 $Z$ 的取值, 判断序列的趋势变化情况: 若 $Z$ 大于 0 则 表示序列呈现增加趋势, 小于 0 则表现为下降趋势。 对于给定的显著性水平 $\alpha$, 若 $|Z| \leq Z_{1-\alpha / 2}$, 则接 受原假设 $\mathrm{H}_{0}$, 即该序列在 $\alpha$ 显著性水平趋势不显著; 若 $|Z| \geq Z_{1-\alpha / 2}$, 则拒绝原假设, 即该序列在 $\alpha$ 显 著性水平存在明显的变化趋势。

\subsection{2. 连续小波变换分析方法 ${ }^{[23]}$}

小波变换利用一系列小波函数来表征时间序列 的信号, 小波函数是小波变换的基础, 它是具有震荡 性、能够迅速衰减到零的一类函数, 它们可以通过平 移、压缩或拉伸基本函数得到。该基本函数称为母小 波, 假设 $\psi_{0}(t)$ 为母小波函数, 本研究选择 Morlet 函 数作为母小波函数, 其数学形式定义如下:

$$
\psi_{0}(t)=\pi^{-1 / 4} e^{i \omega_{0} t} e^{-t^{2} / 2}
$$

其中, $\omega_{0}$ 是无量纲频率参数, $t$ 为无量纲的时间 变量。对于给定的信号 $f(t)$, 其连续小波变换信实质 为 $f$ 与小波函数的卷积, 可表示为:

$W_{f}(a, b)=\sum_{t=0}^{N=1} f(t) \psi^{*}\left[\frac{(t-b) \delta t}{a}\right]$ 其中, $\psi^{*}$ 为母小波 $\psi_{0}$ 的复共轭函数, $a$ 为尺度参数, 反映不同尺度的伸缩, $b$ 位置参数, 反映时间轴上的 平移, 可以通过修改参数 $a$ 和 $b$ 来变换尺度和位置; $W_{f}(a, b)$ 为小波变换系数, 它是参数 $a$ 和 $b$ 的函数, 反映了不同尺度和时间轴上不同位置处的小波函数 与信号的逼近程度。

本研究采用连续小波变换 (CWT) 分析湘江流 域极端降水及极端径流序列多尺度的变化特征, 并进 一步分析两者变化的一致性。

\section{4. 湘江流域水文极值的时空演变特征}

计算湘江流域 27 个水文站点的主要水文极值指 标, 使用 Mann-Kendall 检验方法和 ArcGIS 中的空间 分析工具（Spatial Analyst Tools）分析了该流域极端 径流和极端水位的时空演变特征。

\section{1. 极端径流变化的时空特征}

极端径流分析选取了年、夏季（6-8 月）超 95\% 分位数径流发生频次、最大日径流量、连续 3 天最大 径流量、连续 5 天最大径流量共 8 项指标进行趋势分 析和突变检测。

\subsection{1. 极端径流的趋势检验和突变分析}

表 1 总结了湘江流域各水文站年、夏季超 $95 \%$ 分位数径流发生频次、最大日径流、连续 3 天最大径 流、连续 5 天最大径流在 0.1 显著性水平下的 Mann-Kendall 趋势分析结果。极端径流的分析结果显 示, 在 $90 \%$ 置信水平下, 湘江流域大部分站点的年极 端径流变化比较平缓未表现显著增加趋势, 仅 1 个站 点表现为显著减小趋势; 而汛期 6-8 月份的夏季极端 径流在 26\%水文站显著增加, 其中夏季日最大径流、 连续 3 天最大径流、夏季连续 5 天最大径流、超 $95 \%$ 分位数的极端径流频次呈现上升趋势的站点分别为 $7 \% 、 7 \% 、 19 \% 、 7 \%$ 。

从 Mann-Kendall 典型站点极端径流突变检测结 果 (图 2) 可以发现, 表现显著增长趋势站点的极端 径流序列多数发生了突变, 突变时间集中在 20 世纪 90 年代附近, 这与王家祁 ${ }^{[24]}$ 对中国大洪水时序分布 规律的研究结果一致, 即 90 年代以后进入第三次洪 水高频期。 
Risk Analysis and Crisis Response in Big Data Era (RAC-16)

表 1. 极端径流 Mann-Kendall 趋势分析结果

\begin{tabular}{lc||lc}
\hline 极端径流指标 & $\begin{array}{c}0.1 \\
\text { 显著性水平下 } \\
\text { 站点数 }\end{array}$ & 极端径流指标 & $\begin{array}{c}\text { 显著性水平下 } \\
\text { 站点数 }\end{array}$ \\
\hline 年最大日径流 & $1(-)$ & 夏季最大日径流 & $3(2+, 1-)$ \\
年最大 3 日径流 & $1(-)$ & 夏季最大 3 日径流 & $3(2+, 1-)$ \\
年最大 5 日径流 & $1(-)$ & 夏季最大 5 日径流 & $6(5+, 1-)$ \\
年超 95 分位数径流频次 & $1(-)$ & 夏季超 95 分位数径流频次 & $4(2+, 2-)$ \\
\hline 注. 湘江流域 27 个流量观测站, “+”表示上升趋势, “-”表示下降㑇势
\end{tabular}

注: 湘江流域 27 个流量观测站; “+” 表示上升趋势, “一”表示下降趋势

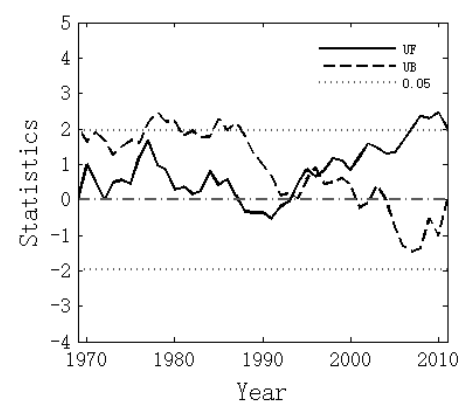

A 老埠头站夏季最大 3 日径流 1995

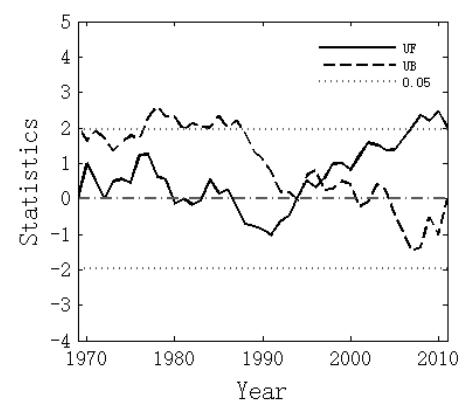

C 老埠头站夏季最大 5 日径流 1992

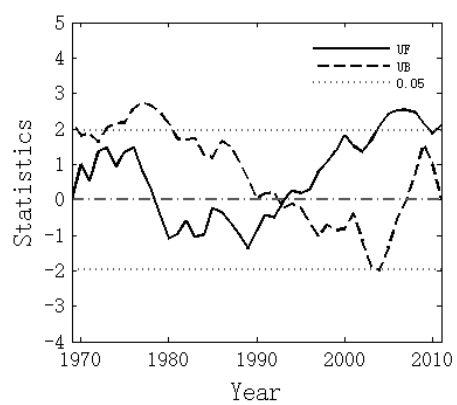

B 椰州站夏季最大 3 日径流 1993

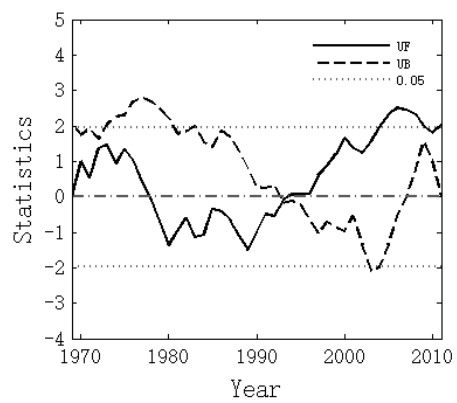

D 椰州站夏季最大 5 日径流 1985

图 2. 湘江流域典型站点夏季极端径流的 Mann-Kendall 突变检测

\subsection{2. 极端径流变化的空间特征}

本文在对极端径流进行 Mann-Kendall 趋势分析 过程中, 得到的水文站点极端径流的多年 Kendall 斜 率度 $\beta$, 可以确定各水文站不同极端径流指标的平均 变化幅度, 在 ArcGIS 中采用反距离权重法 (IDW) 进行空间插值, 可以得到极端径流变化的空间差异。

图 3 展示的是极端径流指标的标准化 $\beta$ 值的空间 分布规律, 从年最大日径流、连续 3 天最大径流、连 续 5 天最大径流、极端径流频次 (图 3-a、b、c、d)
四个极端径流指标 $\beta$ 值的空间分布可以看出, 湘江下 游和中游部分流域的极端径流呈现增加趋势, 即涟水 流域所有的极端径流指标均呈现增加的趋势, 涓水、 蒸水流域的极端径流频次指标呈现增加的趋势; 而湘 江干流的极端径流指标普遍表现下降趋势。此外, 湘 江下游左侧支流极端径流频次的增加趋势表明该流 域洪水事件发生频繁, 洪水风险增大。 
Risk Analysis and Crisis Response in Big Data Era (RAC-16)
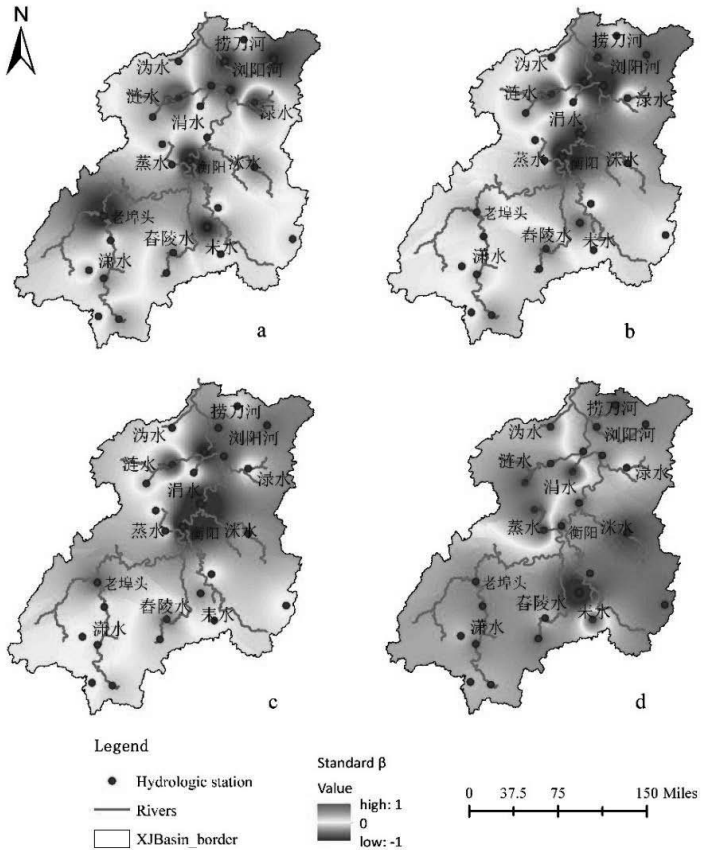

图 3. 年最大日径流 (a)、连续 3 天最大径流 (b)、连续 5 天最大径流 (c)、极端径流频次 (d) 的 M-K 趋势分析标准化 $\boldsymbol{\beta}$ 值的空间分布

\section{2. 极端水位变化的时空特征}

极端水位分析选取了超 95 分位数水位发生频次、 极端水位（第 95 分位数）、年最大日水位进行 Mann-Kendall 趋势分析和突变检测。在趋势分析结果 的基础上，利用 ArcGIS 的空间分析工具对极端水位 的空间分布特征进行了分析。

\subsection{1. 极端水位的趋势检验和突变分析}

表 2 总结了湘汇流域 19 个水文站年超 95 分位数
水位发生频次、极端水位 (第 95 分位阈值)、年最大 日水位在 0.1 和 0.05 显著性水平下的趋势分析结果。 极端水位的分析结果显示, 湘江流域年超 95 分位数 水位发生频次、极端水位（第 95 分位阈值）、年最大 日水位, 在 $90 \%$ 置信水平下表现显著的增加趋势的站 点数分别为 $21 \% 、 21 \% 、 11 \%$; 在 $95 \%$ 置信水平下, 表现显著的增加趋势的站点数分别为 $16 \% 、 21 \% 、 5 \%$ 。

表 2. 极端水位 Mann-Kendall 趋势分析结果

\begin{tabular}{lcc}
\hline 极端水位指标 & 0.1 显著性水平下站点数 & 0.05 显著性水平下站点数 \\
\hline 超 95 分位数水位频次 & $12(4+, 8-)$ & $11(3+, 8-)$ \\
极端水位 (95 分位阈值) & $12(4+, 8-)$ & $12(4+, 8-)$ \\
最大日水位 & $4(2+, 2-)$ & $3(1+, 2-)$ \\
\hline \multicolumn{1}{c}{ 注: 湘江流域 19 个水位观测站: “+” 表示上升趋势, “-”表示下降趋势 }
\end{tabular}

\subsection{2. 极端水位变化的空间特征}

本文在对极端水位指标进行 Mann-Kendall 趋势 分析过程中, 得到的水文站点极端水位指标的多年 Kendall 斜率度 $\beta$, 可以确定各水文站不同极端水位
指标的平均变化幅度, 同样采用反距离权重法 (IDW) 进行空间插值，可以得到各极端水位指数的空间差异。 从图 4 年极端水位、年最大日水位、极端水位频 
Risk Analysis and Crisis Response in Big Data Era (RAC-16)

次（图 4-a、b、c) 三个极端水位指标 $\beta$ 值的空间分 布图可以得出, 位于湘江中游的春陵水上游的极端水 位（第 95 分位阈值）呈上升趋势，而湘江上游的潇
水以及中游春陵水的极端水位频次有增大的趋势; 湘 江下游和中游的左侧支流的极端水位指数普遍表现 下降趋势。

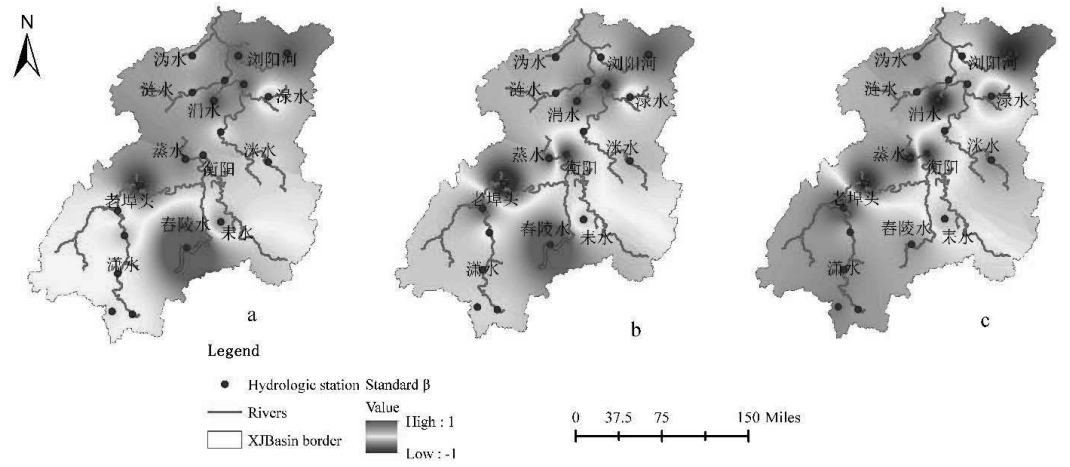

图 4. 年极端水位 (a)、年最大日水位 (b)、极端水位频次 (c) 的 M-K 趋势分析标准化 $\beta$ 值的空间分布

\section{5. 结论与讨论}

多项研究表明极端气候条件的改变是导致水文 极值的变化的主要原因 ${ }^{[14,15,25,26]}$ 。本文针对湘江流域 极端径流、极端水位的时空变化特征分别开展了独立 的分析, 可以得到如下结论: (1) 湘江流域大部分站 点的年极端径流指标未表现显著的变化趋势 $(\mathrm{p}<0.1)$, 夏季极端径流在 $26 \%$ 水文站显著增加。空间分布结果 表明湘江中游和下游部分流域的年极端径流呈现增 加趋势。(2) 在 $90 \%$ 置信水平下, 年极端水位指标表 现显著的增加趋势的站点数分别为 $21 \% 、 21 \% 、 11 \%$, 极端水位显著增加的站点主要分布在湘江中游和上 游地区。

为了进一步确定极端径流对极端降水的响应特 征, 本文采用连续小波变换的方法来分析比较河川径 流量与对应极端降水的变化特征以及两者之间的变 化关系, 进而分析极端径流与极端降水变化关系的一 致性。

本文选取分别位于湘江流域上中下游的江华、未 阳和朗梨三个站点, 对其夏季最大流量和降水序列的 时间一频率变化特征进行分析。图5 是运用Morlet连 续小波方法对标准化的夏季流量或降水序列的分析 结果, 反映了各个站点夏季最大日流量和降水序列小 波变换系数实数部分的分布情况, 图中红色区域表示 小波变换系数的高值区,而蓝色区域代表系数的低值 区, 值越大则周期越显著。

从图 5 可以看出, 不同尺度上极端降水和极端径
流信号均表现出相似的变化模式。其中上游极端径流 和极端降水序列 (图5-A1和A2) 变化的主要振荡周 期基本一致, 45年间均发生一次振荡, 周期尺度为 10-15 年, 发生在 1972-1974 年、1982-1984 年、 1994-1996年、2006-2008年，高值时期分别为1973、 1983、1995、2007年。中游极端径流和极端降水序列 (图5-B1和B2) 也发生一次振荡, 振荡周期尺度为 11-13 年, 发生在 1982-1984 年、1994-1996年、 2005-2008年, 与上游相似的是, 1980 s以后的高值时 期也发生在1983、1995、2007年。下游极端径流 (图 5-C1）发生一次振荡, 周期尺度为20-25年, 发生在 1970-1975年、1995-1999年, 高值时期为1973、1997 年; 极端降水序列 (图5-C2) 发生两次振荡, 第一次 振荡周期尺度为20-25年, 发生在1970-1975年, 高值 时期为1973年, 在1979年左右发生突变振荡周期尺度 变为13-17年, 发生在1979-1983年、1995-1999年、 2008-2012年，高值时期为1981、1997、2010年。

综上, 小波分析确定了湘江流域夏季极端径流和 降水存在显著相关关系, 即该流域夏季极端径流对极 端降水有极强的响应, 表明极端降水是影响该流域洪 水风险的主要因子。加强该区域的暴雨预报对于防洪 减灾具有重要意义。此外, 该流域下游的极端径流和 极端降水信号虽然也表现出了一定的相似性, 但较上 游和中游有所下降, 可能与下游地区较为强烈的人类 活动影响有关, 这将在进一步研究中做深入探讨。 
Risk Analysis and Crisis Response in Big Data Era (RAC-16)

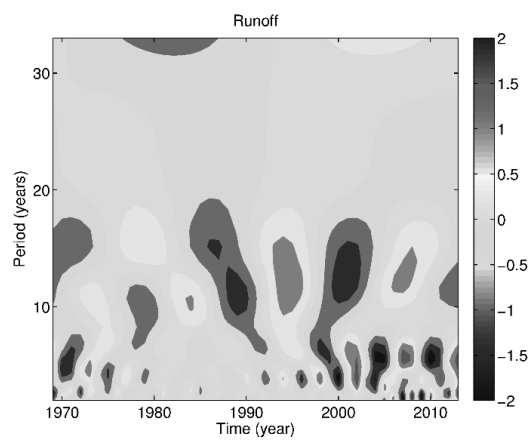

A1 上游潇水-江华站 夏季最大日流量

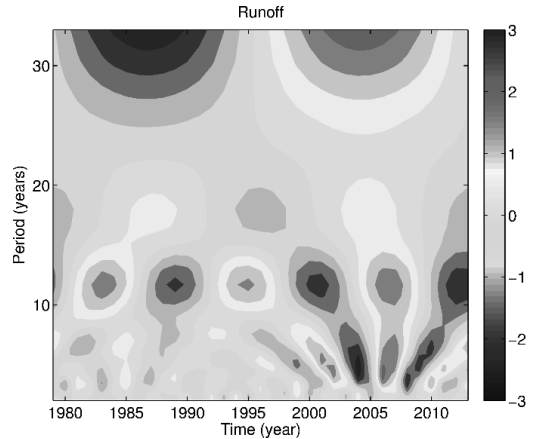

B1 中游末水-末阳站夏季最大日流量

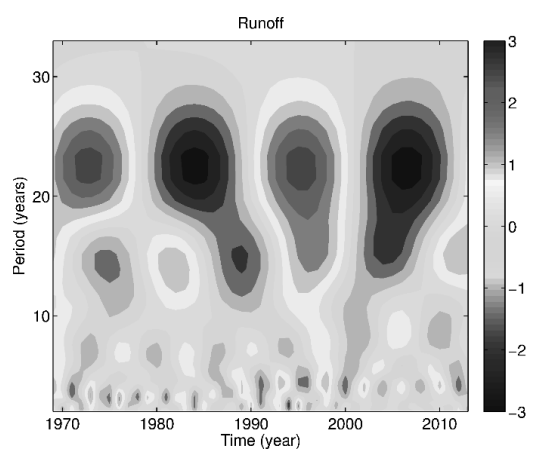

C1 下游汶阳河-朗梨站 夏季最大日流量

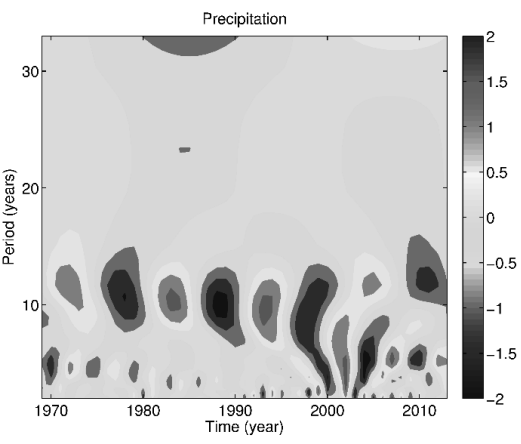

A2 上游潇水-江华站 夏季最大日降水

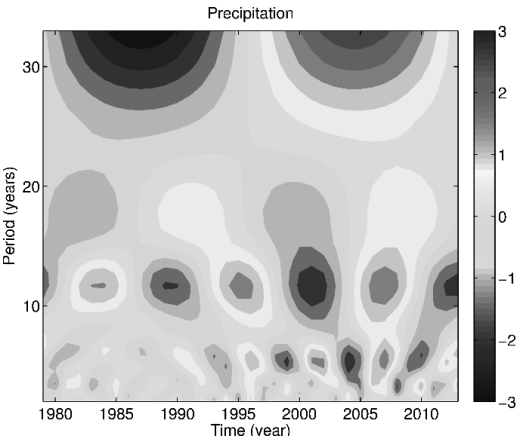

B2 中游末水-未阳站 夏季最大日降水

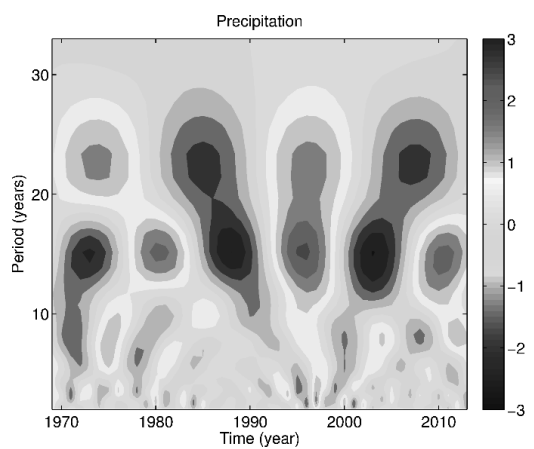

C2 下游汶阳河-朗梨站 夏季最大日降水

图 5. 湘江流域上中下游代表站点年最大流量和降水的小波变换分析结果

注: 中游来阳水文站为 1979 年设站, 故本文对该站分析时所采用的径流和降水数据的时间为 1979-2013 年。 
Risk Analysis and Crisis Response in Big Data Era (RAC-16)

\section{参考文献}

[1] IPCC. Climate change 2007. Cambridge, United Kingdom and New York, USA: 2007.

[2] 杜鸿, 夏军, 曾思栋, 等. 淮河流域极端径流的 时空变化规律及统计模拟. 地理学报. 2012(03): 398-409.

[3] Cheng X, Sun H, Zhang Y. Flood disaster risk assessment and spatial distribution characteristics along the Yangtze River in Anhui Province. Journal of Risk Analysis and Crisis Response. 2014, 4(4): 238-242.

[4] Milly P, Wetherald R T, Dunne K A, et al. Increasing risk of great floods in a changing climate. NATURE. 2002, 415(6871): 514-517.

[5] Keef C, Svensson C, Tawn J A. Spatial dependence in extreme river flows and precipitation for Great Britain. Journal of Hydrology. 2009, 378(3- 4): 240-252.

[6] Burn D H, Sharif M, Zhang K. Detection of trends in hydrological extremes for Canadian watersheds. HYDROLOGICAL PROCESSES. 2010, 24(13): 1781-1790.

[7] Glaser R, Riemann D, Schoenbein J, et al. The variability of European floods since AD 1500. CLIMATIC CHANGE. 2010, 101(1-2SI): 235 256.

[8] 刘九夫, 张建云, 关铁生. 20 世纪我国暴雨和洪 水极值的变化. 中国水利. 2008(2): 35-37.

[9] 陶望雄, 贾志峰. 渭河干流中段近50a径流极值变 化特征分析. 中国农村水利水电. 2015(09): 7-11.

[10] 陈波, 方伟华, 何飞, 等. 湘江流域洪涝灾害与 降水的关系. 自然灾害学报. 2008(01): 92-96.

[11] 杜鹃, 徐伟, 赵智国, 等. 湘江流域近 30 年径流 量与水位的长期变化规律研究. 应用基础与工 程科学学报. 2010(03): 369-378.

[12] 肖艳, 黎祖贤, 章新平, 等. 近 48 年来湘江流域 极端降水事件特征分析. 长江流域资源与环境. 2010(11): 1356-1362.

[13] 薛联青, 刘远洪, 张梦泽, 等. 基于样本熵的降 雨和径流时间序列突变检验. 地球科学与环境 学报. 2015(03): 75-80.

[14] Legesse D, Vallet-Coulomb C, Gasse F. Hydrological response of a catchment to climate and land use changes in Tropical Africa: case study South Central Ethiopia. Journal of Hydrology. 2003, 275(1-2): 67-85.
[15] Lahmer W, Pfützner B, Becker A. Assessment of land use and climate change impacts on the mesoscale. Physics and Chemistry of the Earth, Part B: Hydrology, Oceans and Atmosphere. 2001, 26(7): 565-575.

[16] 董全, 陈星, 陈铁喜, 等. 淮河流域极端降水与 极端流量关系的研究. 南京大学学报(自然科学 版). 2009(06): 790-801.

[17] Yang Y, Tian F. Abrupt change of runoff and its major driving factors in Haihe River Catchment, China. Journal of Hydrology. 2009, 374: 373-383.

[18] Zhang Q, Ye X, Werner A D, et al. An investigation of enhanced recessions in Poyang Lake: Comparison of Yangtze River and local catchment impacts. Journal of Hydrology. 2014, 517: 425-434.

[19] Mann H B. Nonparametric tests against trend. ECONOMETRICA. 1945, 13(3): 245-259.

[20] Kendall M G. Rank correlation methods[M]. London: Charles Griffin, 1975.

[21] Gocic M, Trajkovic S. Analysis of changes in meteorological variables using Mann-Kendall and Sen's slope estimator statistical tests in Serbia. Global and Planetary Change. 2013, 100: 172-182.

[22] Du J, Fang J, Xu W, et al. Analysis of dry/wet conditions using the standardized precipitation index and its potential usefulness for drought/flood monitoring in Hunan Province, China. Stochastic environmental research and risk assessment. 2013, 27(2): 377-387.

[23] Niu J, Sivakumar B. Scale-dependent synthetic streamflow generation using a continuous wavelet transform. Journal of Hydrology. 2013, 496: 71-78.

[24] 王家祁, 骆承政. 中国暴雨和洪水特性的研究. 水文. 2006, 26(3): 33-36.

[25] Marengo J A, Alves L M, Soares W R, et al. Two contrasting severe seasonal extremes in tropical South America in 2012: flood in Amazonia and drought in northeast Brazil. Journal of climate. 2013, 26(22): 9137-9154.

[26] Skakun S, Kussul N, Shelestov A, et al. Flood hazard and flood risk assessment using a time series of satellite images: A case study in Namibia. Risk Analysis. 2014, 34(8): 1521-1537. 